\title{
Correlation and path coefficient analysis for yield and its attributing traits in bread wheat (Triticum aestivum L. em Thell)
}

\author{
Tabassum* \\ Department of Genetics and Plant Breeding, College of Agriculture, Govind Ballabh Pant \\ University of Agriculture and Technology, Pantnagar, U.S. Nagar-263145 (Uttarakhand), \\ India

\section{Anil Kumar} \\ Department of Genetics and Plant Breeding, College of Agriculture, Govind Ballabh Pant \\ University of Agriculture and Technology, Pantnagar, U.S. Nagar-263145 (Uttarakhand), \\ India

\section{Deepanker Pandey} \\ Department of Genetics and Plant Breeding, College of Agriculture, Govind Ballabh Pant \\ University of Agriculture and Technology, Pantnagar, U.S. Nagar-263145 (Uttarakhand), \\ India

\section{Birendra Prasad} \\ Department of Genetics and Plant Breeding, College of Agriculture, Govind Ballabh Pant \\ University of Agriculture and Technology, Pantnagar, U.S. Nagar-263145 (Uttarakhand), \\ India
}

${ }^{*}$ Corresponding author. E-mail: tabassum12081992@gmail.com

\begin{abstract}
Grain yield is a complex quantitative trait and influenced by a number of attributes. To obtain higher yield information regarding association of these attributes with yield can serve as a basis in a breeding programme. The present experiment was undertaken to estimate correlation coefficients between grain yield and different contributing characters and divide this association into direct and indirect effects through path coefficient analysis. The experiment was laid-out with three replications in randomized block design using 51 bread wheat genotypes and data were recorded for fourteen metric traits. Results revealed that grain yield per plant possessed highly significant positive associations with biological yield per plant $(0.787$ and 0.606$)$, number of spikelets per spike $(0.565$ and $0.358)$, number of tillers per plant $(0.500$ and 0.383$)$ and spike length $(0.320$ and 0.297$)$ at both genotypic as well as phenotypic level respectively. Biological yield per plant (1.125) exhibited highest positive direct effect on grain yield followed by harvest index (0.678), number of spikelets per spike (0.109), days to maturity $(0.100)$ and spike length $(0.060)$. Therefore, these characters can serve as a selection criterion for further improvement in grain yield of wheat.
\end{abstract}

Keywords: Bread wheat, Correlation coefficient, Grain yield, Path coefficient

\section{INTRODUCTION}

Wheat is one of the most important food grains and served as the principal food in most areas of the world and also occupies eminent position in Indian agriculture. It is a cereal of cool climates having an important role in the food and nutritional security of India. There are various uses of wheat in human feeding including chapatti to processed foods and numerous industrial products for which its flour is specifically suitable (Panghal et al., 2017). In India, 95\% of the cultivated area under wheat represents hexaploid spring type belonging to Triticum aestivum L.em. Thell., which is commonly called bread wheat (Grewal and Goel,

\section{Article Info}

DOI: 10.31018/jans.v10i4.1867

Received: August 15, 2018

Revised: September 12, 2018

Accepted: October 1, 2018

\section{How to Cite}

Tabassum et al. (2018). Correlation and path coefficient analysis for yield and its attributing traits in bread wheat (Triticum aestivum L. em Thell). Journal of Applied and Natural Science, 10(4): $1078-1084$
2015). Bread wheat (Triticum aestivum) is a self pollinated, allo-hexaploid species $(2 n=6 x=42)$ of the family poaceae. Three genomes $A, B$ and $D$ were involved in its evolution (Morris and Sears, 1967) and it has the genome AABBDD. India has 30.23 million hectares area under wheat cultivation with a production of 93.50 million tonnes and productivity of $3093 \mathrm{~kg} / \mathrm{ha}$ (Anonymous, 2016). The major wheat producing states in India are Uttar Pradesh (26.9 million tonne), Punjab (16.11 million tonne) and Haryana (11.14 million tonne) (Tabassum et al., 2017).

Grain yield is a complex quantitative trait greatly influenced by environment and is the result of several yield contributing attributes. Development of 
improved cultivar capable of producing better yield under various agro climatic conditions depends upon the amount of genotypic variability present in a population for the traits (Kumar et al., 2017). The correlation studies are used for the identification of traits positively correlated with grain yield, so that one can accumulate optimum combination of these traits in a common genotype. Correlation analysis that relates grain yield to a single variable may not provide a complete understanding of the importance of each component in determining grain yield. Path coefficient analysis allows partitioning of correlation coefficients into direct and indirect effects. It provides a critical examination of specific traits that produce a given correlation and could be successfully employed in formulating an effective selection strategy (Okuyama et al., 2004). Path coefficient analysis permits the partitioning of correlation coefficient into direct and indirect effects and facilitates the estimation of contribution of each component (independent cause) on grain yield (dependent variable) (Khan et al., 2005, Suleiman et al., 2014). Study of genotypic and phenotypic correlations among yield contributing plant characters and their direct or indirect effects on yield is important and pre requisite to increase grain yield per unit area (Kumar et al., 2015). Therefore, the experiment was framed with the following objectives: i) To estimate genotypic and phenotypic correlation coefficients among grain yield and yield contributing traits and ii) To identify direct and indirect effects of different yield attributes on grain yield.

\section{MATERIALS AND METHODS}

The present investigation was undertaken at the Norman E. Borlaug Crop Research Centre of Govind Ballabh Pant University of Agriculture and Technology, Pantnagar, India during rabi 2014-15 in timely sown condition using 51 bread wheat genotypes. The experiment was carried out using randomized block design with three replications. Data were recorded for fourteen metric traits viz., plant height, number of tillers per plant, flag leaf area, peduncle length, spike length, number of spikelets per spike, number of grains per spike, grain weight per spike, 1000 grain weight, biological yield per plant, grain yield per plant and harvest index on individual plant basis on a sample of five randomly selected competitive plants. However days to $75 \%$ heading and days to maturity were recorded on per plot basis. To test the significance of differences between treatments, analysis of variance was done as suggested by Panse and Sukhatme (1967). Phenotypic and genotypic correlation coefficients were calculated as given by Kwon and Torrie (1964). Path coefficient analysis was done according to the procedure given by Wright (1921) and further elaborated by Dewey and Lu (1959). Path coefficient analysis was car- ried out by taking grain yield per plant as dependent variable and other observed traits as independent variables. Thirteen yield contributing characters were considered in path coefficient analysis to estimate their direct and indirect effects.

\section{RESULTS AND DISCUSSION}

The analysis of variance revealed the presence of highly significant $(P<0.01)$ differences among genotypes for all the traits in bread wheat (Triticum aestivum). This indicated the presence of considerable amount of diversity in the material and sufficient scope for further improvement in these characters (Table 1). Coefficient of variation ranged from 1.194 (Days to Maturity) to 13.285 (Flag leaf area).

\section{Correlation coefficient analysis}

Genotypic correlations for different characters: In present investigation inter character associations were measured at both genotypic and phenotypic levels. Genotypic correlations for different characters studied are presented in Table 2. Days to $75 \%$ heading possessed highly significant positive correlation with days to maturity (0.556), flag leaf area (0.223) and harvest index (0.312) but significant positive correlation with spike length (0.165) and highly significant negative correlation with number of tillers per plant ($0.265), 1000$-grain weight (-0.294), biological yield per plant $(-0.466)$ and grain yield per plant $(-0$. $551)$. Days to maturity showed highly significant positive correlation with plant height $(0.411)$ and peduncle length (0.501) and highly significant negative correlation with number of tillers per plant ($0.352)$, biological yield per plant $(-0.396)$ and grain yield per plant $(-0.551)$. Number of tiller per plant showed highly significant positive correlation with spike length (0.221), number of spikelets per spike $(0.322)$, grain weight per spike $(0.212)$, biological yield per plant (0.670) and grain yield per plant $(0.500)$ and highly significant negative correlation with harvest index $(-0.451)$. Plant height exhibited highly significant positive correlation with flag leaf area (0.472), peduncle length $(0.724)$, spike length (0.424), number of grains per spike $(0.374)$ but significant negative correlation with grain weight per spike $(-0.203)$ and harvest index (0.161 ). Flag leaf area exhibited highly significant positive correlation with peduncle length (0.969), spike length (0.757), biological yield per plant $(0.440)$ and highly significant negative association with number of spikelets per spike $(-0.283), 1000-$ grain weight $(-0.478)$ and harvest index $(-0.496)$. Similarly, peduncle length showed highly significant positive correlation with spike length (0.651) but highly significant negative correlation with number of spikelets per spike (-0.376), 1000-grain weight $(-0.299)$, grain yield per plant $(-0.227)$ and harvest index (-0.394). Likewise spike length pos- 
Tabassum et al. / J. Appl. \& Nat. Sci. 10 (4): 1078 -1084 (2018)

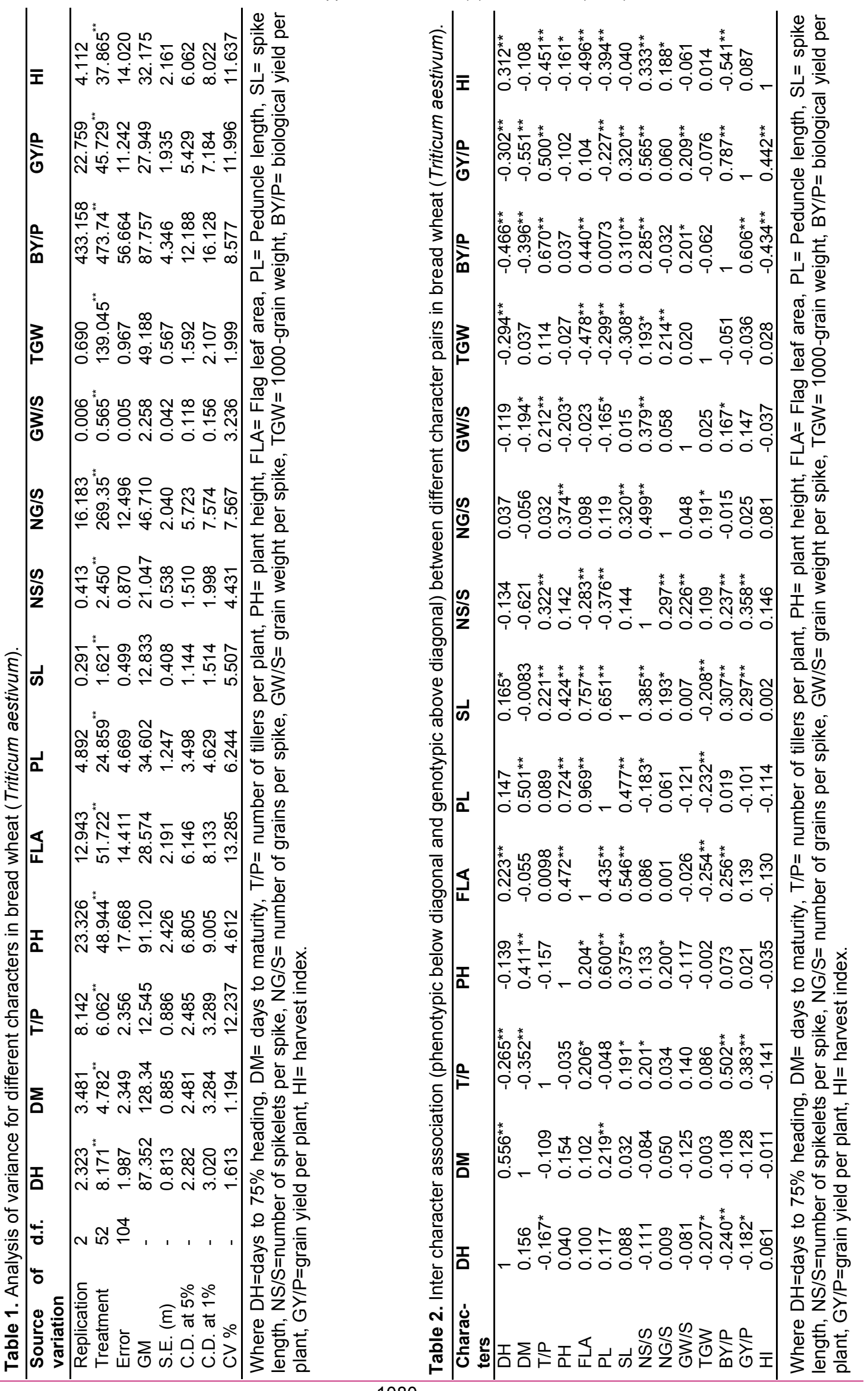


sessed highly significant positive association with number of grains per spike (0.320), biological yield per plant (0.310) and grain yield per plant $(0.320)$ but highly significant negative correlation with 1000-grain weight $(-0.308)$. Number of spikelets per spike was highly significantly and positively correlated with number of grains per spike (0.499), grain weight per spike (0.379), biological yield per plant (0.285), grain yield per plant $(0.565)$ and harvest index (0.333) and it showed significant positive association with 1000-grain weight (0.193). Number of grains per spike showed significant positive correlation with 1000grain weight (0.214) and harvest index (0.188). Grain weight per spike showed highly significant positive correlation with grain yield per plant (0.209) and significant positive correlation with biological yield per plant (0.201). Biological yield exhibited highly significant positive correlation with grain yield per plant $(0.787)$ but highly significant negative correlation with harvest index $(-0.541)$.

Phenotypic correlations for different characters: The phenotypic correlation coefficients for different traits have been presented in Table 2 . Days to $75 \%$ heading showed highly significant negative correlation with biological yield per plant $(-0.240)$ but significant negative correlation with number of tillers per plant $(-0.167), 1000$-grain weight $(-0.207)$ and grain yield per plant $(-0.182)$. Highly significant positive correlation with peduncle length (0.219) was observed for days to maturity. Number of tillers per plant exhibited highly significant positive association with biological yield per plant (0.502) and grain yield per plant (0.383), it showed significant positive correlation with flag leaf area (0.206), spike length $(0.191)$ and number of spikelets per spike (0.201). Plant height showed highly significant positive correlation with peduncle length (0.600) and spike length (0.375) and significant positive correlation with flag leaf area (0.204) and number of grains per spike (0.200). Flag leaf area possessed highly significant positive correlation with peduncle length (0.435), spike length (0.546) and biological yield per plant $(0.256)$ but significant negative correlation with 1000 -grain weight $(-0.254)$. Peduncle length expressed highly significant positive correlation with spike length (0.477), highly significant negative correlation with 1000 -grain weight (0.232 ) and significant negative correlation with number of spikelets per spike (-0.183). Highly significant positive correlation was observed for spike length with number of spikelets per spike (0.385), biological yield per plant (0.307) and grain yield per plant $(0.297)$ but highly significant negative correlation with 1000 -grain weight $(-0.208)$, it showed significant positive correlation with number of grains per spike (0.193). Number of spikelets per spike showed highly significant positive correlation with grain yield per plant $(0.358)$, bio- logical yield per plant $(0.237)$, number of grains per spike (0.297) and grain weight per spike. Significant positive correlation was observed for number of grains per spike with 1000-grain weight (0.191). Grain weight per spike exhibited significant positive association with biological yield per plant (0.167) and biological yield per plant possessed highly significant positive correlation with grain yield per plant (0.606) but highly significant negative correlation with harvest index $(-0.434)$. Grain yield per plant showed highly significant positive correlation with biological yield per plant (0.606), harvest index (0.442), number of tillers per plant $(0.383)$, number of spikelets per spike (0.358), spike length (0.297) and significant negative correlation with days to $75 \%$ heading $(-0.182)$. The correlation coefficient analysis is a way to measure the degree of association between any two traits and provides us the nature and degree of association among yield and yield contributing traits. These associations help us to perform indirect selection for better yielding genotypes. Experimental findings of the present investigation revealed that grain yield per plant possessed highly significant positive correlation with number of tillers per plant, spike length, number of spikelets per spike and biological yield per plant at both phenotypic and genotypic levels. These findings are in agreement of earlier findings obtained by Avinashe et al. (2015) by estimating correlation among grain yield and its contributing traits using 14 bread wheat (Triticum aestivum) genotypes and also by Khan et al. (2015) in their study of correlation among yield and yield contributing traits using 24 bread wheat (Triticum aestivum) genotypes. Grain yield per plant have highly significant and positive phenotypic correlation with harvest index, significant negative correlation with days to $75 \%$ heading and negative correlation with days to maturity. At genotypic level, grain yield had highly significant and positive correlation with number grain weight per spike and highly significant negative correlation with days to heading, days to maturity and negative correlation with plant height. The positive relationships between grain yield and these different yield component traits reflect promising scope of improvement in grain yield in new genotypes. Highly significant positive correlation of number of tillers per plant with biological yield per plant and grain yield per plant was observed at both phenotypic and genotypic level indicated that more number of tillers leads to increase grain yield. Similar results were also obtained by Munir et al. (2007) for number of tillers per plant with biological yield per plant and grain yield per plant working with bread wheat genotypes (Triticum aestivum). Spike length was found to have highly significant positive phenotypic and genotypic correlation with number of spikelets per spike, number of grains per spike, biologi- 
cal as well as grain yield per plant, also number of spikelets per spike found correlated with number of grains per spike, grain weight per spike, biological yield per plant and grain yield per plant. These results indicated that with increase in values of all these traits a direct improvement in grain yield can be seen. So there is a possibility that we can perform indirect selection for grain yield based on all these traits. Such types of findings were previously obtained by Desheva ( 2016) when they found positive correlation of spike length with number of spikelets per spike, number of grains per spike and number of spikelets per spike was found positively correlated with number of grains per spike, grains weight per spike and grain yield per plant using winter bread wheat varieties. Galalcha and Hanchinal (2013) found spike length was positively correlated with biological yield per plant while working with bread wheat genotypes.

Path coefficient analysis: Path coefficient analysis was carried out using genotypic correlation coefficients of different yield contributing traits. Grain yield was considered as resultant variable and rest of the thirteen traits as casual variables. The results of path analysis are presented in Table 3 .

Direct effects: Path analysis revealed that biological yield per plant (1.125) exerted highest positive direct effects towards the grain yield per plant, followed by harvest index (0.678), number of spikelets per spike $(0.109)$, days to maturity $(0.100)$, spike length $(0.060)$, peduncle length (0.030), number of tillers per plant $(0.019)$, however grain weight per spike $(-0.023)$, number of grains per spike $(-0.046)$, flag leaf area $(-0.051)$, thousand grain weight $(-0.052)$, days to $75 \%$ heading $(-0.064)$ and plant height $(-0.103)$ exerted negative direct effects towards grain yield per plant.

Indirect effects: Days to $75 \%$ heading had made highest positive indirect effects towards grain yield through harvest index followed by days to maturity, 1000-grain weight, plant height, spike length, peduncle length, grain weight per spike and indirect negative effects through number of grains per spike, number of tillers per plant, flag leaf area, number of spikelets per spike, and biological yield per plant. Days to maturity had positive indirect effects through days to $75 \%$ heading, peduncle length, plant height and 1000 -grain weight while indirect negative effects through number of grains per spike, flag leaf area, harvest index, spike length, grain weight per spike, number of tillers per plant, biological yield per plant and number of spikelets per spike. Likewise, number of tillers per plant exerted positive contribution via biological yield per plant, number of spikelets per spike, spike length, grain weight per spike, 1000-grain weight, peduncle length, flag leaf area, number of grains per spike, while its indirect effects through plant height, days to $75 \%$ heading, days to maturity and harvest index on grain yield were found negative. Plant height's indirect effect through grain weight per spike was maximum followed by harvest index, number of tillers per plant, days to $75 \%$ heading, 1000-grain weight were positive, while its indirect effects through biological yield per plant, number of spikelets per spike, days to maturity, number of grains per spike, spike length, flag leaf area and peduncle length were found negative. Flag leaf area caused positive indirect effects through harvest index, 1000-grain weight, number of spikelets per spike, days to maturity, grain weight per spike and it exhibited negative indirect effects via number of grains per spike, number of tillers per plant, days to $75 \%$ heading, biological yield per plant, plant height, spike length and peduncle length. Peduncle length exhibited highest positive indirect effects through flag leaf area followed by plant height, spike length, days to maturity, days to $75 \%$ heading, number of grains per spike, number of tillers per plant and biological yield per plant and negative indirect effects through grain weight per spike, 1000-grain weight, harvest index and number of spikelets per spike. Spike length had positive indirect effects via. Flag leaf area, peduncle length, plant height, number of grains per spike, biological yield per plant, number of tillers per plant, days to $75 \%$ heading, number of spikelets per spike and grain weight per spike and negative indirect effects was observed through harvest index, days to maturity and 1000-grain weight. Positive indirect effects through number of grains per spike, grain weight per spike, harvest index, number of tillers per plant, biological yield per plant, 1000-grain weight, plant height and spike length were exerted by number of spikelets per spike while its indirect effects through days to $75 \%$ heading, flag leaf area, peduncle length and days to maturity were found negative. Likewise, number of grains per spike exhibited positive indirect effects via days to maturity and biological yield per plant. It had negative indirect effects through days to $75 \%$ heading, number of tillers per plant, grain weight per spike, flag leaf area, peduncle length, harvest index, 1000-grain weight, spike length, plant height and no. of spikelets per spike. Grain weight per spike showed positive indirect effects through plant height, days to maturity, peduncle length, days to $75 \%$ heading, harvest index and flag leaf area also it exhibited negative indirect effects via spike length, 1000-grain weight, number of grains per spike, number of tillers per plant, biological yield per plant and number of spikelets per spike. 1000 -grain weight showed positive indirect effects through flag leaf area, spike length, peduncle length, days to $75 \%$ heading, biological yield per plant and plant height. It had exerted negative effects through harvest index, grain weight per 


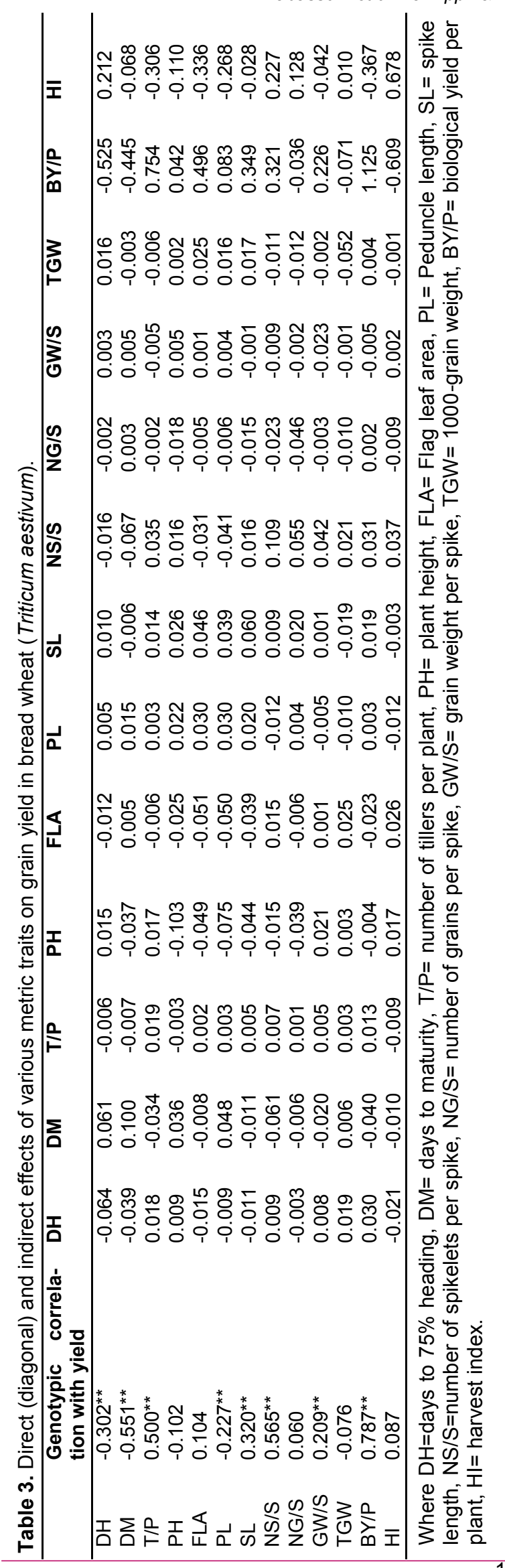

spike, days to maturity, number of tillers per plant, no. of spikelets per spike and number of grains per spike. Biological yield per plant exhibited positive indirect effects through number of tillers per plant, flag leaf area, spike length, number of spikelets per spike, grain weight per spike, peduncle length and plant height. It exerted negative contribution towards yield via number of grains per spike, 1000-grain weight, days to maturity, days to $75 \%$ heading and harvest index. Harvest index had positive indirect effects via number of spikelets per spike, days to $75 \%$ heading, number of grains per spike and 1000-grain weight while negative indirect effects was shown through spike length, grain weight per spike, days to maturity, plant height, peduncle length, number of tillers per plant, flag leaf area and biological yield per plant.

Simple correlation analysis that relates grain yield to a single variable may not provide a complete understanding of the importance of each component in determining grain yield. The path coefficient analysis provides a way to understand the actual causal factor by dividing correlation between traits into direct and indirect effects via other traits. Khan et al. (2005) earlier reported that plant height had positive indirect effects through no of tillers per plant, 1000-grain weight, spike length through plant height on grain yield working with bread wheat genotypes and Yadav et al. (2013) reported that number of spikelets/ear and ear length had positive direct effect on grain yield using 49 bread wheat genotypes of different origin whereas Kumar et al. (2016) observed similar kind of direct effects of days to $75 \%$ heading, days to maturity, number of tillers per plant and spike length on grain yield.

In the present investigation results revealed that grain yield per plant possessed highly significant positive association with four major yield contributing traits namely number of tillers per plant, spike length, number of spikelets per spike and biological yield per plant. This positive association provides the basis of indirect selection for yield improvement. Further path analysis shown that days to $75 \%$ heading and number of grains per spike possessed highest indirect contribution through harvest index towards grain yield, whereas number of tillers per plant, flag leaf area, peduncle length, spike length, number of spikelets per spike, grain weight per spike and 1000-grain weight exhibited maximum indirect contribution through biological yield per plant. These results suggested that by improving biological yield per plant and other positively associated traits grain yield could be improved.

\section{Conclusion}

In the present investigation significant differences were observed for all the traits studied viz., days to $75 \%$ heading, days to maturity, plant height, 
number of tillers per plant, flag leaf area, peduncle length, spike length, number of spikelets per spike, number of grains per spike, grain weight per spike, 1000 grain weight, biological yield per plant, grain yield per plant and harvest index, indicating presence of good amount of variability in the bread wheat (Triticum aestivum) genotypes. Furthermore, grain yield per plant possessed highly significant positive associations with biological yield per plant $(0.787$ and 0.606$)$, number of spikelets per spike (0.565 and 0.358$)$, number of tillers per plant $(0.500$ and 0.383$)$ and spike length (0.320 and 0.297$)$ at genotypic as well as phenotypic level respectively, indicating stable effect of these traits on grain yield and this indicate that indirect selection for yield will be more effective based on these traits. Path analysis revealed that biological yield per plant made greater contribution towards grain yield as it exhibited highest positive direct effect (1.125) on grain yield per plant followed by harvest index (0.678), number of spikelets per spike (0.109), days to maturity (0.100), spike length (0.060), peduncle length (0.030) and number of tillers per plant (0.019). Based on these results it can be concluded that for the improvement of grain yield, indirect selection for higher number of tiller per plant, more spike length, number of spikelets per spike, grains per spike and higher biological yield per plant should be considered.

\section{REFERENCES}

1. Anonymous (2016). Progress Report of All India Coordinated Wheat and Barley Improvement Project, 2015-16, Project Director"s Report. Ed: G.P. Singh, ICAR-Indian Institite of Wheat and Barley Research, Karnal, India. p96.

2. Avinashe, H.A., Shukla, R.S., Dubey, N. and Jaiwar, S. (2015). Correlation and path analysis for yield and yield contributing characters in bread wheat (Triticum aestivum L.). Electronic Journal of Plant Breeding, 6 (2): 555-559.

3. Desheva, G. (2016). Correlation and path-coefficient analysis of quantitative characters in winter bread wheat varieties. Trakia journal of sciences, (1): 2429.

4. Dewey, D.R. and LU, K.H. (1959). A correlation and path-coefficient analysis of components of crested wheatgrass seed production. Agronomy Journal, 51 (8): 515- 518.

5. Galalcha, S. and Hanchinal, R.R. (2013). Correlation and path analysis in yield and yield components in spring bread wheat (Triticum aestivum L.) genotypes under irrigated condition in Southern India. African Journal of Agriculture Research, 8(29): 3186-3192.

6. Grewal, S. and Goel, S. (2015). Current research status and future challenges to wheat production in India. Indian Journal of Biotechnology, 14: 445-454.

7. Khan, A.J., Azam, F., Ali, A., Tariq, M. and Amin, M. (2005). Inter-relationship and Path Coefficient Analy- sis for Biometric Traits in Drought Tolerant Wheat (Triticum aestivum L.). Asian Journal of Platn Sciences, 4 (5): 540-543.

8. Khan,W .C., Mohammad,F., Khan,F. U., Zafar, F. Z. and Ghuttai, G. (2015). Correlation Studies among Productions Traits in Bread Wheat under Rainfed Conditions. American-Eurasian J. Agric. \& Environ. Sci., 15(10): 2059-2063.

9. Kumar, A., Harshwardhan, Kumar, A. and Prasad, B. (2015). Estimation of correlation coefficient for yield and quality parameters of bread wheat under Tarai region of Pantnagar. Annals of Platn and Soil Research, 17(2) special issue: 224-228.

10.Kumar, A., Joshi, G., Jaiswal, J.P., Kumar, A. and Prasad, B. (2016). Path analysis for yield and yield contributing traits in wheat (Triticum aestivum L. em Thell) germplasm. Progressive Research-An International Journal, 11 (special V): 2986-2989.

11.Kumar, A., Swati, Kumar, A. and Prasad, B. (2017). Study of percent contribution of Line x Tester components for morpho-physiological heat tolerance traits in bread wheat. Environment and pharmacological life science, 6(3): 339-342.

12.Kwon, S.H. and Torrie, J.H. (1964). Heritability and inter-relationship among traits of two soybean populations. Crop Sci., 4: 196-198.

13.Morris, R. and Sears, E.R. (1967). "The cytogenetics of wheat and its relatives. In: Wheat and Wheat Improvement (Quisenberry KS and Reitz LP, Eds.)." American Society of Agronomy, Madison, 19-87.

14.Munir, M. Chowdhry, M.A. and Malik, T.A. (2007). Correlation Studies among Yield and its Components in Bread Wheat under Drought Conditions. Int. J. Agri. Biol., 9(2): 287-290.

15.Okuyama, L.A., Federizzi, L.C. and Neto, J.F.B. (2004). Correlation and path analysis of yield and its components and plant traits in wheat. Ciencia Rural, Santa Maria., 34(6): 1701-1708.

16.Panghal, A., Chhikara, N. and Khatkar, B.S. (2017). Characterisation of Indian wheat varieties for chapatti (flat bread) quality. Journal of the Saudi Society of Agricultural Sciences, http://dx.doi.org/10.1016/ j.jssas.2017.02.005.

17.Panse, V. G. and Sukhatme, P. V. (1967). Statistical Methods of Agricultural Workers. 2nd Endorsement, ICAR Publication, New Delhi, India, pp-381.

18.Suleiman, A.A., Nganya, J.F. and Ashraf, A. (2014). Correlation and Path Analysis of Yield and Yield components in some 221 Cultivars of Wheat (Triticum Aestivum L) in Khartoum State, Sudan. Journal of forest products \& industries, 3(4): 198-203.

19.Tabassum, Kumar, A. and Prasad, B. (2017). Study of combining ability and nature of gene action for yields and its contributing traits in bread wheat (Triticum aestivum L.em. Thell.). International journal of current microbiology and applied sciences, 6(10): 3562-3573.

20.Wright S. (1921). Systems of mating. Genetics, 6(1): 11-78.

21.Yadav, A., Kumar, A., Roy, C. and Jaiswal, J.P. (2013). Correlation and Path-coefficient analysis for grain yield, its components and quality traits in bread wheat. Pantnagar Journal of Research, 11(3):337-341 